\title{
A new mathematical hull-form with 10-shape parameters for evaluation of ship response in waves
}

\author{
Sadaoki Matsui ${ }^{1}$ (D)
}

Received: 4 December 2020 / Accepted: 26 August 2021 / Published online: 20 September 2021

(c) The Author(s) 2021

\begin{abstract}
This study presents a new mathematical hull-form that is expressed as an explicit function with 10 hull-form parameters, which is called the Matsui hull-form in this study. The proposed hull-form was developed by expanding the modified Wigley hull-form so that the following 10 hull-form parameters can be independently varied: main dimensions $L, B, d$, fineness coefficients $C_{b}, C_{\mathrm{m}}, C_{\mathrm{w}}$, second moment of waterplane area coefficient $C_{\mathrm{w} 2}$, longitudinal center of buoyancy LCB and floatation $\mathrm{LCF}$, and a parameter $\beta$ related to anterior-posterior asymmetry. The main purpose of this hull-form is that it is utilized for the following two objects: the first is the simple evaluation of the seakeeping performance and wave loads in the early ship designing stage without any detailed offset data, and the second is a systematical study on the influence of a ship's dimensions on the ship response in waves. This paper presents the derivation of the Matsui hull-form and the applicability of the proposed hull-from was confirmed by comparing the ship response in waves with the actual ships. Moreover, a sensitivity analysis of the ship response in waves was conducted as an example of the application of the proposed hull-form.
\end{abstract}

Keywords Ship response in waves · Principal dimensions of ship · Mathematical hull-form · Ship design

List of symbols

$A_{\mathrm{w}} \quad$ Waterplane area $\left[\mathrm{L}^{2}\right]$

$B \quad$ Beam [L]

$C_{\mathrm{b}} \quad$ Block coefficient

$C_{\mathrm{m}} \quad$ Midship section area coefficient

$C_{\mathrm{w}} \quad$ Waterplane area coefficient

$C_{\mathrm{w} 2} \quad$ Coefficient of the 2 nd moment of the waterplane area around the $y$-axis

$d \quad$ Mean draft [L]

$g \quad$ Acceleration due to gravity $\left[\mathrm{MLT}^{-2}\right]$

$k_{\mathrm{yy}} \quad$ Radius of gyration of the pitch [L]

$L \quad$ Length between the perpendiculars [L]

$N \quad$ Internal parameter of the mathematical hull-form that is not affected by the principal parameters

$S \quad$ Integrated value of the longitudinal function of the second term of the mathematical hull-form

$X_{1-3} \quad$ Parameters of the mathematical hull-form related to the longitudinal shape

$Z_{1,2} \quad$ Parameters of the mathematical hull-form related to the vertical shape

Sadaoki Matsui

matsui-s@m.mpat.go.jp

1 National Maritime Research Institute, 6-38-1, Shinkawa, Mitaka, Tokyo, Japan $\alpha \quad$ Longitudinal stretching factor of the hull-form

$\beta \quad$ Anterior-posterior asymmetric parameter related to the second moment of the waterplane area around the $y$-axis

$\chi \quad$ Wave angle [deg]

$\rho \quad$ Density of sea water $\left[\mathrm{ML}^{-3}\right]$

$\xi_{\mathrm{B}} \quad \xi$-Coordinate of longitudinal center of buoyancy $(=\mathrm{LCB} /(L / 2))$

$\xi_{\mathrm{F}} \quad \xi$-Coordinate of longitudinal center of floatation $(=\mathrm{LCF} /(L / 2))$

$\zeta_{\mathrm{a}} \quad$ Amplitude of incident wave [L]

$\nabla \quad$ Displacement $\left[\mathrm{L}^{3}\right]$

* $\quad$ Subscripted symbol that indicates the variable is in the aft part $(a)$ or fore part $f$

$\begin{array}{ll}\text { Abbreviations } \\ \text { BC } & \text { Bulk carrier } \\ \text { CS } & \text { Container ship } \\ \text { DOF } & \text { Degrees of freedom } \\ \text { HBM } & \text { Horizontal bending moment } \\ \text { HSF } & \text { Horizontal shear force } \\ \text { LCG } & \text { Longitudinal center of gravity } \\ \text { LCB } & \text { Longitudinal center of buoyancy } \\ \text { LCF } & \text { Longitudinal center of floatation } \\ \text { RAO } & \text { Response amplitude operator } \\ \text { TM } & \text { Torsional moment }\end{array}$


VBM Vertical bending moment

VSF Vertical shear force

\section{Introduction}

The wave-induced ship motion and wave load can be reasonably estimated by performing numerical calculations such as the strip method or the three-dimensional panel method in these days, and the obtained load is commonly applied for a ship structural analysis. However, simple and explicit formulae that are provided by the classification society's rule, such as in [1], are very useful when designing the ship structure. This is because the details of the ship structure have not been decided during the early stage of development. In recent years, it has been required to further improve the accuracy and versatility of the classification society's rule by clarifying the contribution rate of the principal hull-form parameters to the ship responses, such as the length $L$, beam $B$, draft $d$, block coefficient $C_{\mathrm{b}}$, and waterplane area coefficient $C_{\mathrm{w}}$. It is important even for ship structural designers to know the impact of the hull-form on the ship responses for understanding the physical mechanism of the ship-wave interaction and improvement of the ship structural design.

Regarding the influence of the ship's dimensions on the ship's responses, Bales [2] first proposed a method to improve the hull-form from the viewpoint of a seakeeping ability. Bales defined a seakeeping index with several main ship dimensions that were obtained by regression analysis. Following that study, a lot of related studies have been carried out. For example, Sayli [3] and Cakici [4] recently proposed a data analysis approach to extract the dominant hull-form parameters and their influence from a ship motion database. Apart from these studies, Jensen [5, 6] proposed a semi-analytical approach to develop simplified formulae of wave-induced ship motion and a VBM that is based on the strip theory, which explicitly includes the hull-form shape parameters.

As another approach different from the above study to know the contribution rate of the hull-form parameters to ship response in waves, the sensitivity analysis is one of the most effective and direct methods. To conduct the sensitivity analysis, it is desirable to have a hull-form in which the shape parameters can vary. In this regard, Lackenby [7] has demonstrated how to change a hull-form to vary hull-form parameters individually, but the method needs parent hull-form and lacks simplicity for comprehensive sensitivity analysis. When the emphasis is put on simplicity, the mathematical hull-form is a quite effective way to generate hull-form. For example, the Wigley hullform $[8,9]$ is well-known mathematical hull-form which is expressed by a simple power function, and the modified Wigley hull-form [10] was later proposed by expanding the Wigley hull-form so that it is closer to the actual hullform. These mathematical hull-forms are widely used as a ship model in experimental studies and numerical calculations $[11,12]$; however, they are not suitable for sensitivity analysis to evaluate the ship response in waves, because they have few parameters that can change hull-form and it is not clear how the parameter should be changed to satisfy the desired ship dimensions.

Under these circumstances, this study was conducted to develop a new mathematical hull-form, which is called the Matsui hull-form in this study, for the purpose of simple evaluation of the seakeeping performance and wave load in early designing stages. The Matsui hull-form is expressed by an explicit function with 10 principal hull-form shape parameters, and it is possible to vary the parameters independently over a wide range. In addition, the ship responses in waves of the Matsui hull-form are equivalent to those of the actual ship which has the same shape parameters. Therefore, proposed hull-form can be utilized for a systematical study on the influence of a ship's dimensions on the ship response in waves. Moreover, proposed hull-form enable a simple evaluation of the seakeeping performance and wave loads in the early ship designing stage, because it needs only 10 main dimensions of ship without any detailed offset data.

This study is based on the following fundamental idea: the ship response in waves is mainly dominated by the broad topography of the ship and minor modifications of hull-form are secondary [13]. This fact is generally accepted, and this allows a rough estimation of the seakeeping performance or wave loads in the early design phase where the bodylines have not been determined [2-6]. Furthermore, this study focused on not only the simplicity but also the physical meaning of hull-form parameters. In the process of development of the Matsui hull-form, in addition to principal particulars of ship, some dominant parameters with physical meaning for the ship response in waves were introduced based on theoretical considerations.

This paper presents first detailed process for the development of the Matsui hull-form, and next the ship motion and wave loads of proposed hull-forms are compared to those of actual ships to verify its applicability. For the verification, 154 hull-forms of actual merchant ships were used. Their length ranges from 50 to $400 \mathrm{~m}$ and their ship types are not restricted: bulk carrier, container carrier, ore carrier, oil tanker, LNG carrier, LPG carrier, general cargo ship, RO-RO ship, pure car carrier, etc. [14]. The ship response calculation is based on the linear theory because the proposed hull-form is defined under waterline and is intended for simple estimation. Furthermore, with reference to the parameter ranges of those actual ships, a sensitivity analysis of the hull-form parameter is conducted as an example of the application of the Matsui hull-form. 


\section{Modified Wigley hull-form}

The modified Wigley hull-form is well-known and widely used for experimental and numerical studies. The halfbreadth under the waterline of the hull-form is expressed by the following equation.

$$
\begin{aligned}
\eta= & \left(1-\zeta^{2}\right)\left(1-\xi^{2}\right)\left(1+c_{1} \xi^{2}+c_{2} \xi^{4}\right) \\
& +c_{3} \zeta^{2}\left(1-\zeta^{8}\right)\left(1-\xi^{2}\right)^{4}(0 \leq \xi \leq 1,0 \leq \zeta \leq 1) .
\end{aligned}
$$

$\xi=\frac{x}{L / 2}, \eta=\frac{y}{B / 2}, \zeta=\frac{z}{d}$

where $x, y$, and $z$ are the axes of the longitudinal direction, breadth direction, and depth direction, respectively. The origin is set on the midship, centerline, and waterline of the ship, respectively.

The hull-form can be varied according to the purpose by changing the coefficient $c_{1-3}$. The original Wigley hullform is $c_{1}=c_{2}=c_{3}=0[8,9]$. Although it is extremely simple, the hull-form is far from that of an actual ship. Meanwhile, the parameters $c_{1}, c_{2}$, and $c_{3}$ are attached to the modified Wigley hull-form to render it closer to a realistic one. The values $c_{1}=0.2, c_{2}=0$, and $c_{3}=1$ are normally used for a slender ship $\left(C_{\mathrm{b}}=0.56\right)$ [11], and the values $c_{1}=0.6, c_{2}=1$, and $c_{3}=1$ are normally used for a blunt ship $\left(C_{\mathrm{b}}=0.63\right)$ [12]. The three hull-forms are shown in Fig. 1.

\section{New mathematical hull-form}

Based on the modified Wigley hull-form, a new mathematical hull-form was developed, which is called the Matsui hull-form in this study. The detailed development process of the Matsui hull-form is described in Appendix A, and this section presents a summary of the formulae for the proposed hull-form and some important features of the formulae.

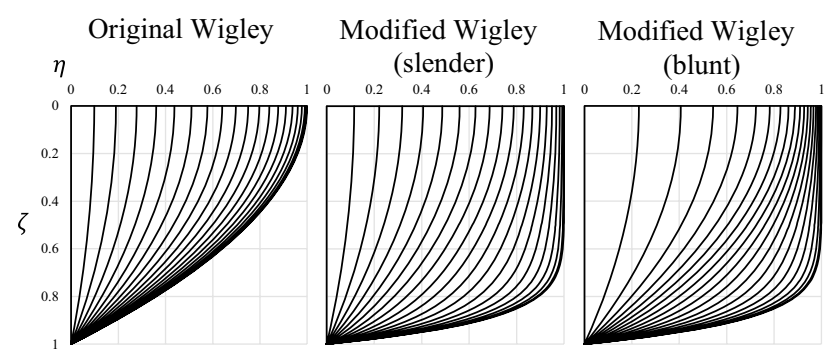

Fig. 1 Original Wigley hull-form and two modified Wigley hullforms
The proposed hull-form is explicitly expressed by 10 hull-form shape parameters: the length $L$, beam $B$, draft $d$, block coefficient $C_{\mathrm{b}}$, midship sectional area coefficient $C_{\mathrm{m}}$, waterplane area coefficient $C_{\mathrm{w}}$, the second moment of the waterplane area coefficient $C_{\mathrm{w} 2}$, the longitudinal center of the buoyancy from the midship LCB, the longitudinal center of floatation from the midship LCF, and a parameter $\beta$ that is related to the anterior-posterior asymmetry in the second moment of the waterplane area. The second moment of the waterplane area coefficient $C_{\mathrm{w} 2}$ is defined as follows.

$C_{\mathrm{w} 2} \equiv \frac{12}{L^{3} B} \iint_{A_{\mathrm{w}}} x^{2} \mathrm{~d} y \mathrm{~d} x$

where $A_{\mathrm{w}}$ is the waterplane area. In Eq. 3, $C_{\mathrm{w} 2}$ is normalized by the factor $1 / 12$ so that $C_{\mathrm{w} 2}=1$ when the waterplane shape is a rectangle, i.e. $L \times B . C_{\mathrm{w} 2}$ is introduced as the hullform shape parameter because it significantly affects the wave-induced vertical motion and the VBM, as explained in Sects. 4 and 5.

The final form of the Matsui hull-form is expressed as the following formula.

$$
\begin{aligned}
\eta= & \left(1-\zeta^{Z_{1 *}}\right)\left\{1-\left(|\xi| / \alpha_{*}\right)^{X_{1 *}}\right\} \\
& +\zeta^{Z_{1 *}}\left(1-\zeta^{Z_{2 *}}\right)\left\{1-\left(|\xi| / \alpha_{*}\right)^{X_{2 *}}\right\}^{X_{3 *}} \\
& \left(-\alpha_{\mathrm{a}} \leq \xi \leq \alpha_{\mathrm{f}}, 0 \leq \zeta \leq 1\right),
\end{aligned}
$$

where

$X_{1 *}=\frac{C_{\mathrm{w} *}}{\alpha_{*}-C_{\mathrm{w} *}}$.

$X_{2 *}=\max \left(N, \frac{C_{\mathrm{b} *}}{\alpha_{*} C_{\mathrm{m}}-C_{\mathrm{b} *}}\right)$ (recommended value).

$X_{3 *}=\left(\frac{C_{\mathrm{b} *}}{\alpha_{*} C_{\mathrm{m}}}\right)^{N \cdot \operatorname{sgn}\left(C_{\mathrm{b} *}-C_{\mathrm{m}} C_{\mathrm{w} *}\right)}$ (recommended value).

$Z_{1 *}=\frac{C_{\mathrm{b} *}-S_{*} C_{\mathrm{m}}}{C_{\mathrm{w} *}-C_{\mathrm{b} *}-S_{*}\left(1-C_{\mathrm{m}}\right)}$.

$Z_{2 *}=\frac{C_{\mathrm{m}}}{1-C_{\mathrm{m}}}-Z_{1 *}=\frac{\frac{\left(C_{\mathrm{w} *} C_{\mathrm{m}}-C_{\mathrm{b} *}\right)}{\left(1-C_{\mathrm{m}}\right)}}{C_{\mathrm{w} *}-C_{\mathrm{b} *}-S_{*}\left(1-C_{\mathrm{m}}\right)}$.

$S_{*}=\alpha_{*} \frac{\Gamma\left(1+X_{3 *}\right) \Gamma\left(1+1 / X_{2 *}\right)}{\Gamma\left(1+X_{3 *}+1 / X_{2 *}\right)}$. 


$$
\begin{aligned}
& \alpha_{*}=2 \sqrt{\frac{C_{\mathrm{w} 2 *}}{C_{\mathrm{w} *}}} \cos \left(\frac{\pi}{3}-\frac{1}{3} \tan ^{-1} \sqrt{\frac{C_{\mathrm{w} 2 *}}{C_{\mathrm{w} *}^{3}}-1}\right) . \\
& { }^{\prime \prime} *^{\prime \prime}=\left\{\begin{array}{c}
\prime \prime a^{\prime \prime} \text { for }-\alpha_{\mathrm{a}} \leq \xi \leq 0 \\
" f^{\prime \prime} \text { for } 0 \leq \xi \leq \alpha_{\mathrm{f}}
\end{array}\right.
\end{aligned}
$$

To express the anterior-posterior asymmetry, the fineness coefficients $C_{\mathrm{b}}, C_{\mathrm{w}}$, and $C_{\mathrm{w} 2}$ are taken separately for the aft part and the fore part of the ship, that is, $C_{\mathrm{ba}}, C_{\mathrm{wa}}, C_{\mathrm{w} 2 \mathrm{a}}$ and $C_{\mathrm{bf}}, C_{\mathrm{wf}}, C_{\mathrm{w} 2 \mathrm{f}}$. The symbol "*" in the subscript for each parameter is replaced with $\varepsilon a \varepsilon$ for the aft part and $\varepsilon f \varepsilon$ for the fore part according to Eq. 12. The coefficients $C_{\mathrm{b} *}, C_{\mathrm{w} *}$, and $C_{\mathrm{w} 2 *}$ are also normalized to unity when the ship is box-shaped, i.e., $L \times B \times d$, and can be obtained approximately by using the anterior-posterior asymmetry parameters as follows.

$$
\left\{\begin{array}{l}
C_{\mathrm{ba}} \cong C_{\mathrm{b}}\left\{1-2 \frac{\mathrm{LCB}}{L}\left(C_{\mathrm{b}}-2\right)^{2}\right. \\
C_{\mathrm{bf}} \cong C_{\mathrm{b}}\left\{1+2 \frac{\mathrm{LCB}}{L}\left(C_{\mathrm{b}}-2\right)^{2}\right.
\end{array}\right\} .
$$

$\left\{\begin{array}{l}C_{\mathrm{wa}} \cong C_{\mathrm{w}}\left\{1-2 \frac{\mathrm{LCF}}{L}\left(C_{\mathrm{w}}-2\right)^{2}\right. \\ C_{\mathrm{wf}} \cong C_{\mathrm{w}}\left\{1+2 \frac{\mathrm{LCF}}{L}\left(C_{\mathrm{w}}-2\right)^{2}\right.\end{array}\right\}$.

$\left\{\begin{array}{l}C_{\mathrm{w} 2 \mathrm{a}}=(1-\beta) C_{\mathrm{w} 2}+\frac{1}{2}\left\{(1+\beta) C_{\mathrm{wa}}^{3}-(1-\beta) C_{\mathrm{wf}}^{3}\right\} \\ C_{\mathrm{w} 2 \mathrm{f}}=(1+\beta) C_{\mathrm{w} 2}-\frac{1}{2}\left\{(1+\beta) C_{\mathrm{wa}}^{3}-(1-\beta) C_{\mathrm{wf}}^{3}\right\}\end{array}\right.$.

$C_{\mathrm{b} *}, C_{\mathrm{w} *}$, and $C_{\mathrm{w} 2 *}$ can also be considered as the input dimensions of the hull-form instead of $C_{\mathrm{b}}, \mathrm{LCB}, C_{\mathrm{w}}, \mathrm{LCF}$, $C_{\mathrm{w} 2}$, and $\beta$.

The proposed hull-form can be generated using Eq. 4-15. A flowchart of the decision process for these parameters is illustrated in Fig. 2. The derivation of Eq. 4-15 and its detailed explanation are described in Appendix A.

Some important features of this hull-form are described below.

a. The power index parameters $X_{1 *}, X_{2 *}, X_{3 *}, Z_{1 *}$, and $Z_{2 *}$ were introduced to generalize the modified Wigley hullform. $X_{2 *}$ and $X_{3 *}$ are the internal DOFs which are not determined by the fineness coefficients. In this paper, the recommended formulae are indicated in Eq. 6 and 7 so that $Z_{1 *}$ and $Z_{2 *}$ do not have a negative value. The parameter $N$ shown in Eq. 6 and 7 is an arbitrary positive real number; however, it should be greater than 1 to

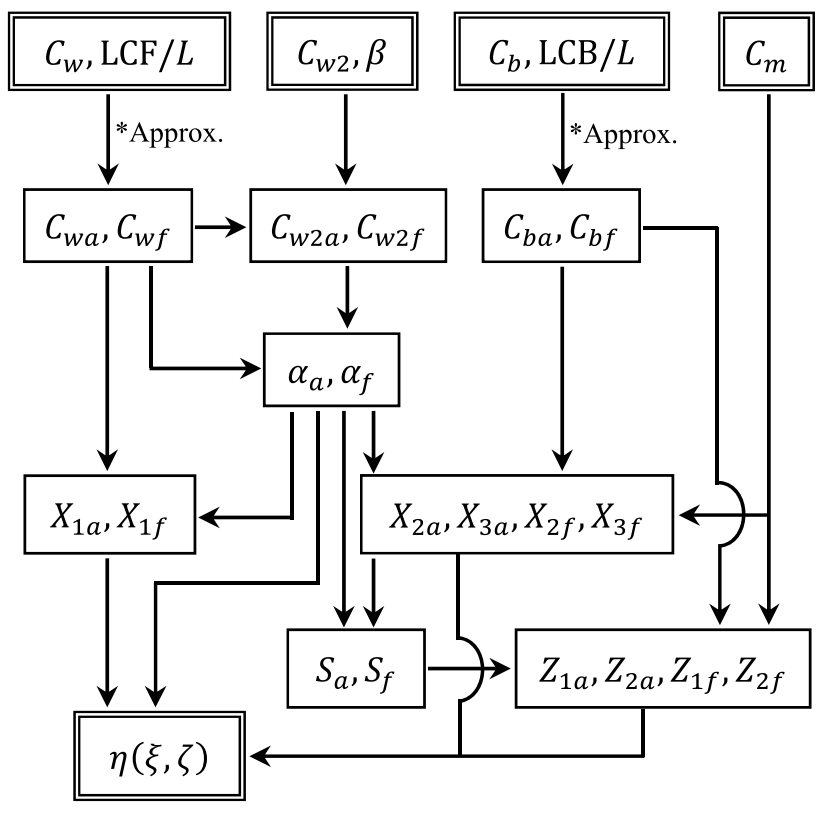

Fig. 2 Flowchart for the generating process of the proposed hull-form

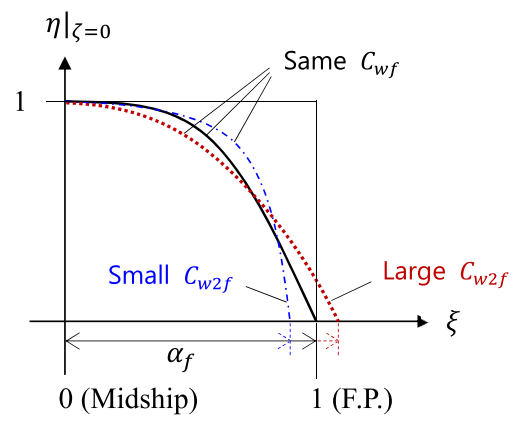

Fig. 3 Schema of stretching the waterplane shape along the $\xi$ axis on the fore part to change $C_{2 \mathrm{wf}}$ without changing $C_{\mathrm{wf}}$

maintain the smoothness of the hull-form at the midship section. In this study, $N$ is set to 2 .

b. The parameter $\alpha_{*}$ is the stretching factor of the $\xi$ axis that can adjust the second moment of the waterplane area. By introducing $\alpha_{*}$, there are two DOFs for the waterplane function, which are $X_{1 *}$ and $\alpha_{*}$.

$\left.\eta\right|_{\zeta=0}=1-\left(\frac{|\xi|}{\alpha_{*}}\right)^{X_{1 *}}$.

Consequently, it is possible to change $C_{\mathrm{w} 2 *}$ so that it is independent from $C_{\mathrm{w} *}$, and this is achieved by stretching the $\xi$ axis, as shown in Fig. 3.

c. The parameter $\beta$ is limited to the region of $-1<\beta<1$, and it determines the rate of the second moment of the waterplane area for the aft and the fore part, $C_{\mathrm{w} 2 *}$ as shown in Eq. 15. An example of the change in the water- 


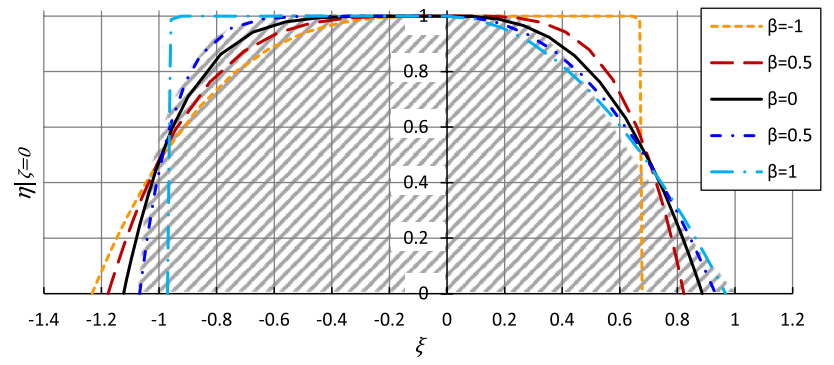

Fig. 4 Change in the waterplane shape by changing $\beta$ without changing $C_{\mathrm{w}}, C_{\mathrm{w} 2}$, and LCF. The shaded area is the actual hull-form

plane shape by $\beta$ is demonstrated in Fig. 4. If $C_{\mathrm{w} *}$ and $C_{\mathrm{w} 2 *}$ are known, $\beta$ can be calculated by applying Eq. 59 . Deciding $C_{\mathrm{w} 2 *}$ with $\beta$ has the following advantages:

1. The change in the hull-form due to $\beta$ is easy to intuitively understand, as depicted in Fig. 4.

2. $\quad \beta$ is a safe parameter, because the hull-form generating process will not fail if it remains within the range of $(-1,1)$.

3. Even if the information of $C_{\mathrm{w} 2 *}$ cannot be obtained, when $\beta=0, C_{\mathrm{w} 2 *}$ can be reasonably determined by applying Eq. 15 and the hull-form becomes realistic.

d. It needs to be noted that Eq. 13 and 14 are approximated formulae, and therefore LCF and LCB of the generated hull-form using Eq. 13 and 14 are slightly different from target value of them. Appendix A describes in detail the error of these approximation and how to obtain $C_{\mathrm{w} *}$ and $C_{\mathrm{b} *}$ that strictly satisfy the target value of LCB and LCF instead of Eq. 13 and 14.

e. The application region of the fineness coefficients for the Matsui hull-form is shown below.

$$
\left\{\begin{array}{l}
0<C_{b *} \leq C_{m}<1 \\
0<C_{w *}<\left(C_{w 2 *}\right)^{1 / 3}
\end{array}\right.
$$

The fineness coefficients of actual ships do not exceed this range. Therefore, it can be said that the proposed hull-form is applicable without the limitation of the hull-form shape parameters.

\section{Validating the applicability for the ship response in waves}

To verify the applicability of the proposed hull-form for evaluating the ship response in waves, this section compares the ship response to waves between the actual ship and the proposed hull-form with the same hull-form parameters as the actual ship. The target ships are the bulk carrier (BC) and the container ship (CS). The hull-form shape parameters and the longitudinal radius of gyration $k_{\mathrm{yy}}$ are listed in Table 1. A comparison of the actual hull-forms and the Matsui hull-forms that are generated based on the parameters in Table 1 are displayed in Figs. 5, 6. The weight distributions of the Matsui hull-forms are identical to those of the actual ships, and the ship speed was uniformly set to $5 \mathrm{kt}$ based on Common Structure Rules [1]. For the calculation of the ship response in waves, the linear analysis code "NMRIW3DLite" based on 3D Green's function method [15] was used. Because the roll motion is excluded in this study, the lateral gyration of the radius was set to be sufficiently large.

A comparison of the RAO for the wave-induced vertical motion, VBM amidship, and VSF at station 7.5 in the head sea (wave angle $\chi=180^{\circ}$ ) is illustrated in Fig. 7. In addition, the wave-induced lateral motion, HBM amidship, HSF, and TM at station 7.5 in the quartering sea $\left(\chi=60^{\circ}\right)$ are depicted in Fig. 8. To demonstrate the effectiveness

Table 1 Main parameters of the target ships

\begin{tabular}{lll}
\hline Parameter & Bulk carrier & Container ship \\
\hline$L(\mathrm{~m})$ & 278 & 283.8 \\
$B(\mathrm{~m})$ & 45 & 42.8 \\
$d(\mathrm{~m})$ & 17.7 & 14 \\
$C_{\mathrm{b}}$ & 0.843 & 0.628 \\
$C_{\mathrm{m}}$ & 0.998 & 0.991 \\
$C_{\mathrm{w}}$ & 0.927 & 0.803 \\
$C_{\mathrm{w} 2}$ & 0.829 & 0.628 \\
$\mathrm{LCG} / L$ from MS & $2.56 \%$ & $-2.16 \%$ \\
$\mathrm{LCF} / L$ from MS & $-0.58 \%$ & $-7.31 \%$ \\
$\beta$ & -0.347 & 0.489 \\
$k_{\mathrm{yy}} / L$ & 0.248 & 0.244 \\
\hline
\end{tabular}

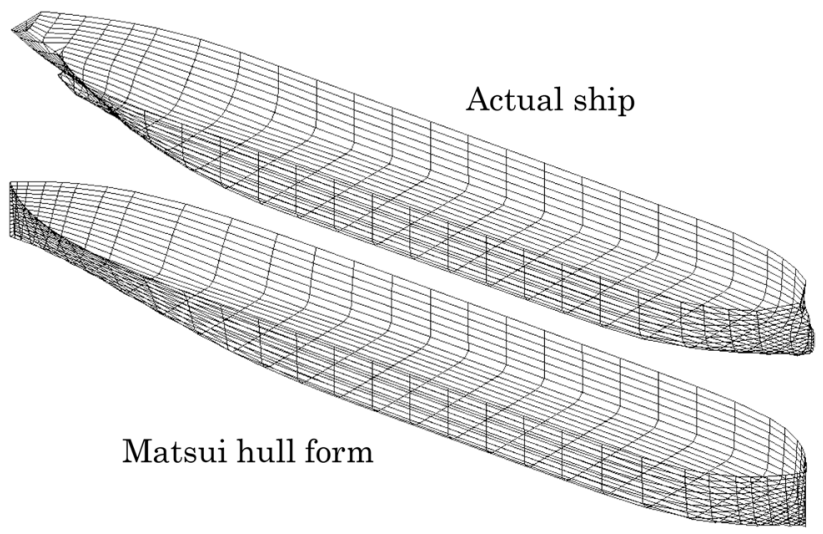

Fig. 5 Comparison of the hull-form under the waterline between the actual ship (above) and the proposed mathematical hull-form (below) of the bulk carrier 


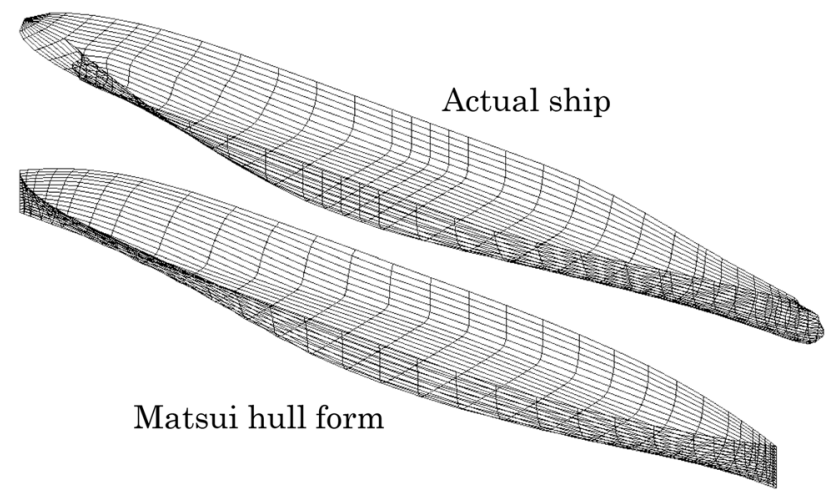

Fig. 6 Comparison of the hull-form under the waterline between the actual ship (above) and the proposed mathematical hull-form (below) of the container ship
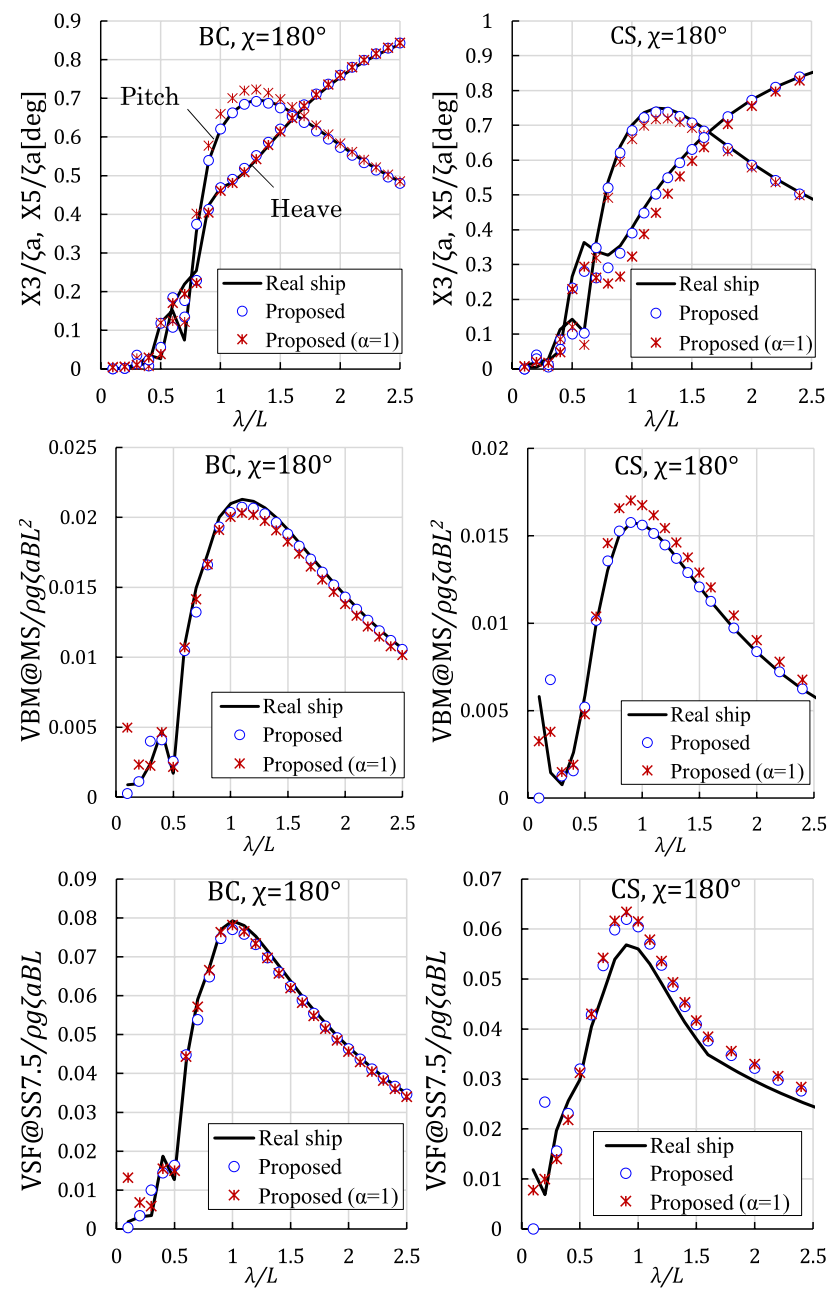

Fig. 7 Comparison of the vertical motion (top), vertical bending moment amidship (middle), and vertical shear force at station 7.5 (bottom) in the head sea between a real ship, the proposed hull-form, and the proposed hull-form that was not stretched by $\alpha$, in regard to the bulk carrier (left) and the container ship (right)
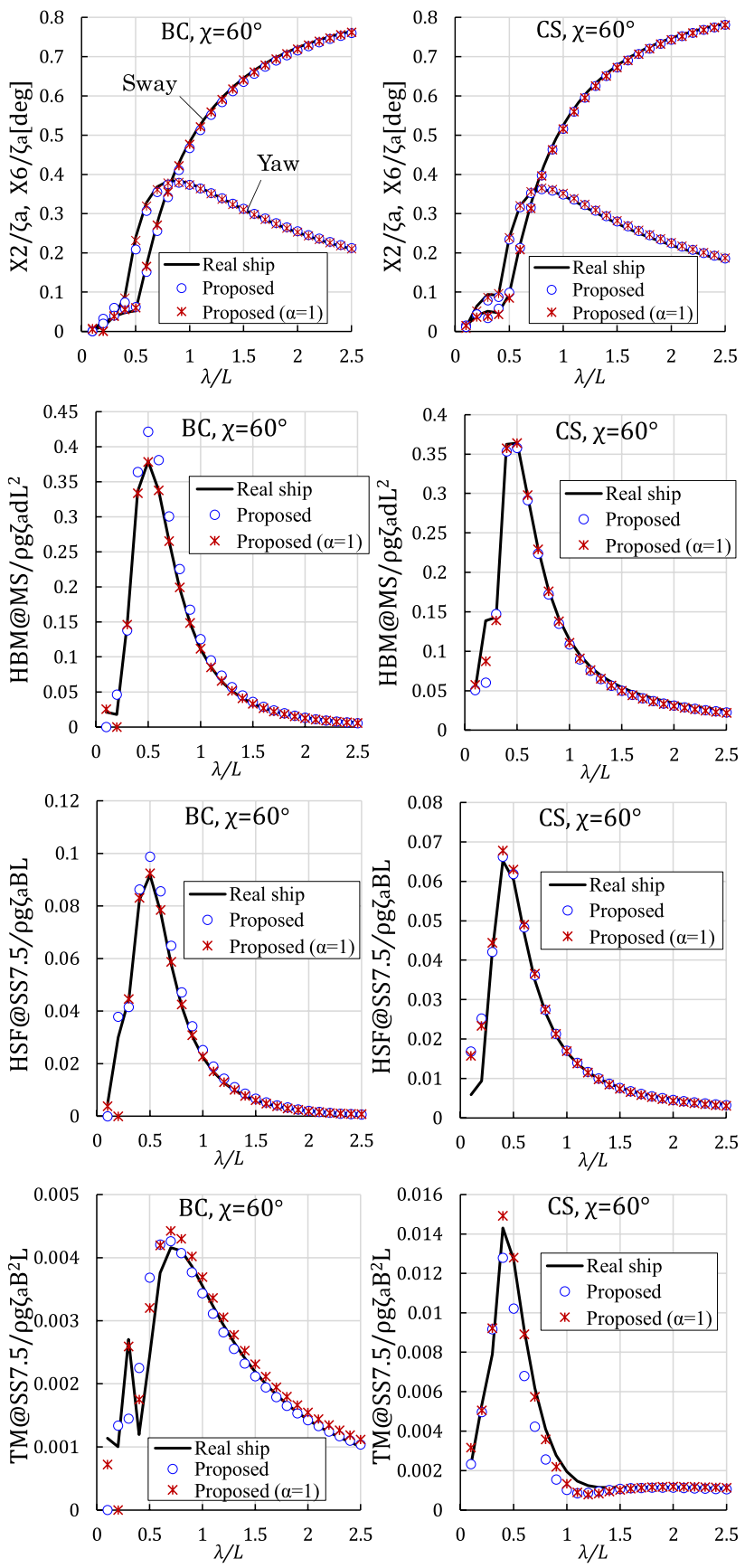

Fig. 8 Comparison of the lateral motion (top), horizontal bending moment amidship (middle top), horizontal shear force at station 7.5 (middle bottom), and torsional moment at station 7.5 (bottom) in the quartering sea between a real ship, the proposed hull-form, and the proposed hull-form that was not stretched by $\alpha$, in regard to the bulk carrier (left) and the container ship (right)

of adjusting $C_{\mathrm{w} 2 *}$ by the stretching factor $\alpha_{*}$, the results of the Matsui hull-form without stretching $\left(\alpha_{*}=1\right)$ are also compared.

From Fig. 7, it is confirmed that the vertical motion and the VBM of the Matsui hull-forms are in good agreement 
with those of the actual ships. In particular, the agreement is significantly improved by adjusting $C_{\mathrm{w} 2}$ in the VBM of the CS. In contrast, when considering the VSF, there is a slight difference between the actual ships and the Matsui hull-forms for the CS. As a result, it can be said that the second moment of the waterplane area is dominant for the vertical motion and the VBM amidship, but not for the VSF at station 7.5. Because the VSF is easily affected by the local distribution of the vertical force, it might be necessary to more accurately reproduce the waterplane shape so that the VSF is closer to that of an actual ship.

From Fig. 8, the lateral motion is not significantly affected by the stretching factor $\alpha_{*}$ and all of them are in good agreement. However, for HBM, HSF, and TM, the non-stretched Matsui hull-form $\left(\alpha_{*}=1\right)$ is closer to an actual ship rather than the stretched Matsui hull-form. The same tendency was confirmed for the other ship types. This is because for the responses that are related to the horizontal force distribution, the projected shape of the ship on the $x-z$ plane might be the dominant dimension. It seems that the horizontal force distribution of the proposed hull-form differs from that of the actual ship owing to the longitudinal stretching when adjusting $C_{\mathrm{w} 2}$. Therefore, when evaluating the response related to the horizontal force using the Matsui hull-form, the stretching factor $\alpha_{*}$ should be set to 1 .

\section{Sensitivity of the ship's main hull-form parameters against the ship response in waves}

In this section, as an example of the application of the Matsui hull-form, the sensitivity of the main parameters of a ship against the ship response in waves is examined. First, the independent non-dimensional hull-form parameters that need to be considered for the analysis are presented. Thereafter, the sensitivities are compared, and the results are examined and discussed in detail.

\subsection{Independent non-dimensional parameters}

Regarding the variables for the sensitivity analysis, nine independent non-dimensional parameters for the proposed hull-form were considered. These parameters are: $B / L, d / B$, $C_{\mathrm{b}}, C_{\mathrm{m}}, C_{\mathrm{w}}, C_{\mathrm{w} 2}, \mathrm{LCB} / L, \mathrm{LCF} / L$, and $\beta$. According to Froude's similarity, the non-dimensional fluid force is unaffected by the scale effect if the Froude number is the same. These nine parameters are necessary and sufficient independent hull-form shape parameters for the RAO. Often, the non-dimensional length $L / \nabla^{1 / 3}[3]$ is considered as a dependent parameter.

$\frac{L}{\nabla^{\frac{1}{3}}}=\left(\frac{L}{B}\right)^{\frac{2}{3}}\left(\frac{B}{d}\right)^{\frac{1}{3}} C_{\mathrm{b}}^{-\frac{1}{3}}$

Note that for the short- or long-term prediction, another dimensional parameter (such as $L$ ) is required because of the scale dependence of the wave spectrum.

In addition to these nine parameters, the non-dimensional radius of gyration of the pitch $\kappa_{y y} / L$ is also used in the sensitivity analysis. The weight distribution, which is needed to calculate the hull-girder sectional forces, was set to a quadratic function distribution that was uniquely determined by $\nabla, \mathrm{LCG}$, and $\kappa_{\mathrm{yy}}$.

The sensitivity analysis can be performed by generating a series of the Matsui hull-forms by varying the hullform parameters and calculating their responses. However, it should be noted that a strong correlation exists between $C_{\mathrm{w}}$ and $C_{\mathrm{w} 2}$. The relationship between $C_{\mathrm{w}}$ and $C_{\mathrm{w} 2}$ for 154 actual merchant ships, which were explained in the introduction, is displayed in Fig. 9. As shown in the figure on the left in Fig. 9, $C_{\mathrm{w} 2}$ is significantly dependent on $C_{\mathrm{w}}$, and in fact, changing $C_{\mathrm{w} 2}$ while fixing $C_{\mathrm{w} 2}$ causes inappropriate changes in the hull-form. Therefore, as an appropriate parameter related to the second moment of the waterplane area that is independent of $C_{\mathrm{w}}$, the following parameter $C_{\mathrm{w} 2}^{\prime}$ is adopted instead of $C_{\mathrm{w} 2}$.

$C_{\mathrm{w} 2}^{\prime} \equiv \frac{C_{\mathrm{w} 2}}{C_{\mathrm{w} 2}^{\alpha=1}}$,

where $C_{\mathrm{w} 2}^{\alpha=1}$ is the value of $C_{\mathrm{w} 2}$ when the waterplane shape has anterior-posterior symmetry and $\alpha_{*}=1$. This is expressed by the following equation.

$C_{\mathrm{w} 2}^{\alpha=1}=12 \int_{0}^{1}\left(\frac{\xi}{2}\right)^{2}\left(1-\xi^{\frac{C_{\mathrm{w}}}{1-C_{\mathrm{w}}}}\right) \mathrm{d} \xi=\frac{C_{\mathrm{w}}}{3-2 C_{\mathrm{w}}}$.
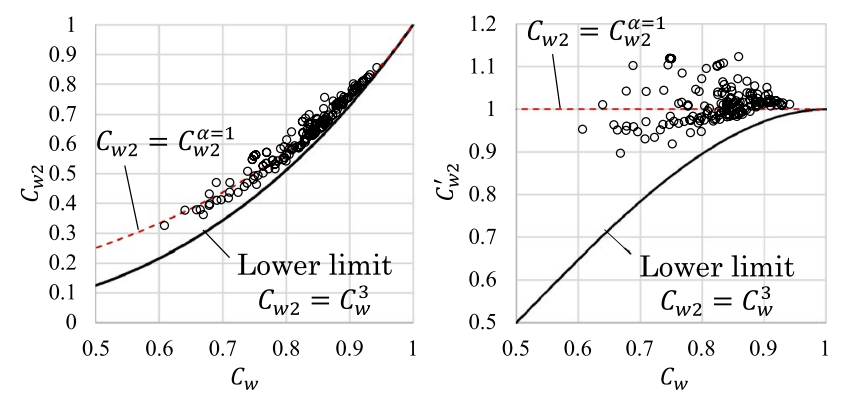

Fig. 9 Relationship between $C_{\mathrm{w}}$ and $C_{\mathrm{w} 2}$ (left), and $C_{\mathrm{w}}$ and $C_{\mathrm{w} 2}^{\prime}$ (right) of actual 154 ships 
The relationship between $C_{\mathrm{w} 2}^{\prime}$ and $C_{\mathrm{w}}$ is shown in the figure on the right in Fig. 9. From this figure, it cannot be confirmed that there is no strong dependence of $C_{\mathrm{w} 2}^{\prime}$ on $C_{\mathrm{w}}$. Figure 10 shows a schema of the change in the hull-form when $C_{\mathrm{w}}$ is changed and $C_{\mathrm{w} 2}^{\prime}$ is fixed. It was determined that fixing $C_{\mathrm{w} 2}^{\prime}$ is almost equivalent to fixing the stretching factor $\alpha_{*}$. Conversely, the change in the hull-form when $C_{\mathrm{w} 2}^{\prime}$ is changed and $C_{\mathrm{w}}$ is fixed is the same as shown in Fig. 3.

Thus, 10 principal non-dimensional parameters were chosen for the sensitivity analysis: $B / L, d / B, C_{\mathrm{b}}, C_{\mathrm{m}}, C_{\mathrm{w}}, C_{\mathrm{w} 2}^{\prime}, \mathrm{LCB} / L, \mathrm{LCF} / L, \beta$, and $\kappa_{\mathrm{yy}} / L$. As a reference for the range of these parameters, Fig. 11

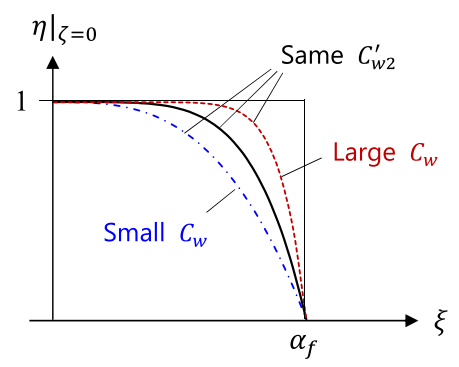

Fig. 10 Schema of the change in the waterplane by changing $C_{\mathrm{w}}$ without changing $C_{2 \mathrm{w}}^{\prime}$ shows the histograms of 154 merchant ships explained in the introduction. Their length ranges from 50 to $400 \mathrm{~m}$ and their ship types are not restricted: bulk carrier, container carrier, ore carrier, oil tanker, LNG carrier, LPG carrier, general cargo ship, RO-RO ship, pure car carrier, etc. [14].

\subsection{Results of the sensitivity analysis}

The variation of the maximum value of the RAO shown in Figs. 7, 8 was investigated when the 10 non-dimensional parameters of the $\mathrm{BC}$ and $\mathrm{CS}$ were changed.

Let us denote the $i$-th hull-form parameter as $p_{i}$ and the $j$-th response as $q_{j}$. Then, the sensitivity of $p_{i}$ against $q_{j}$ is expressed as a partial differential coefficient $\partial q_{j} / \partial p_{i}$. Moreover, to compare their sensitivity for the same index, the "sensitivity factor" defined by the following equation is introduced.

Sensitivity factor $\equiv\left(\frac{\sigma_{p_{i}}}{q_{j}^{\text {rep }}}\right) \frac{\partial q_{j}}{\partial p_{i}}$,

where $q_{j}^{\text {rep }}$ is the representative value of $q_{j}$ for normalization, and the maximum value of each RAO is used in this study. $\sigma_{p_{i}}$ is the standard deviation of the parameter $p_{i}$ obtained from the histogram in Fig. 11. If $p_{i}$ is not
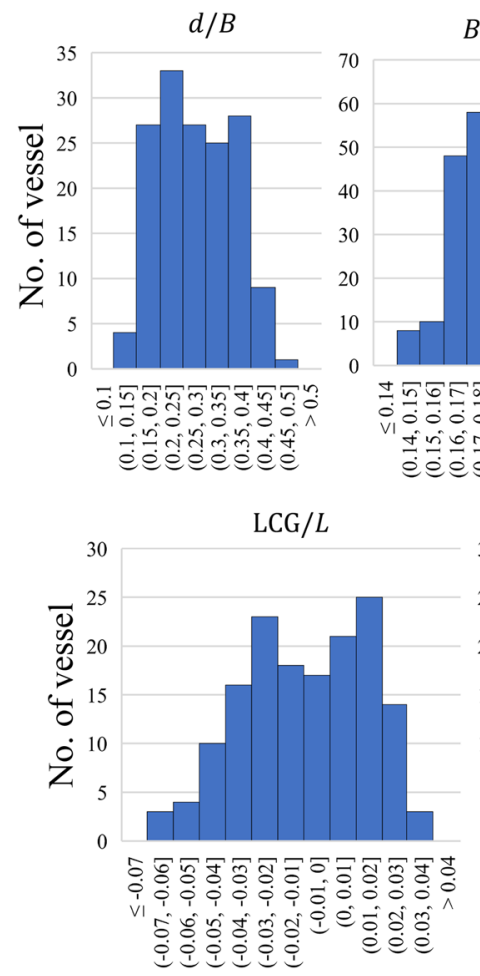

$B / L$
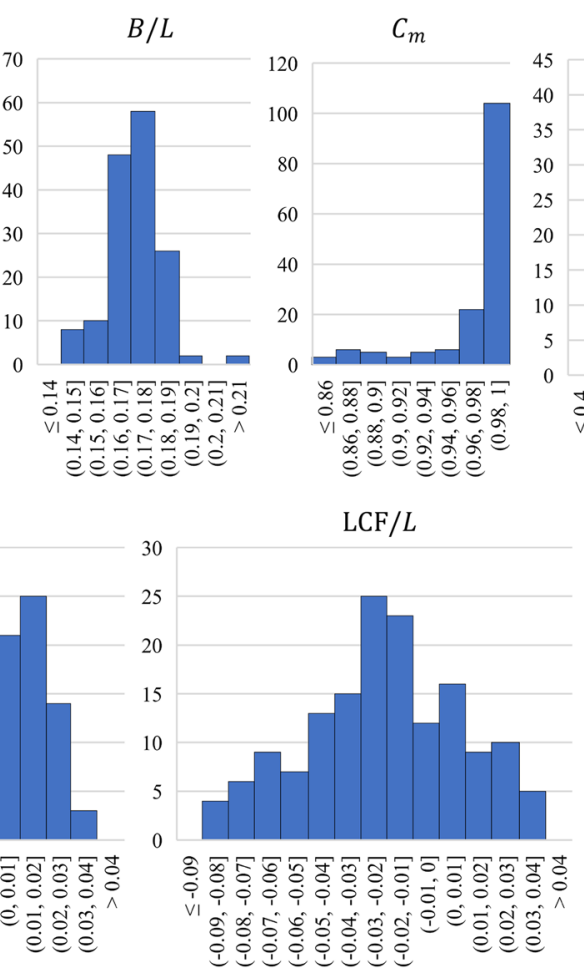
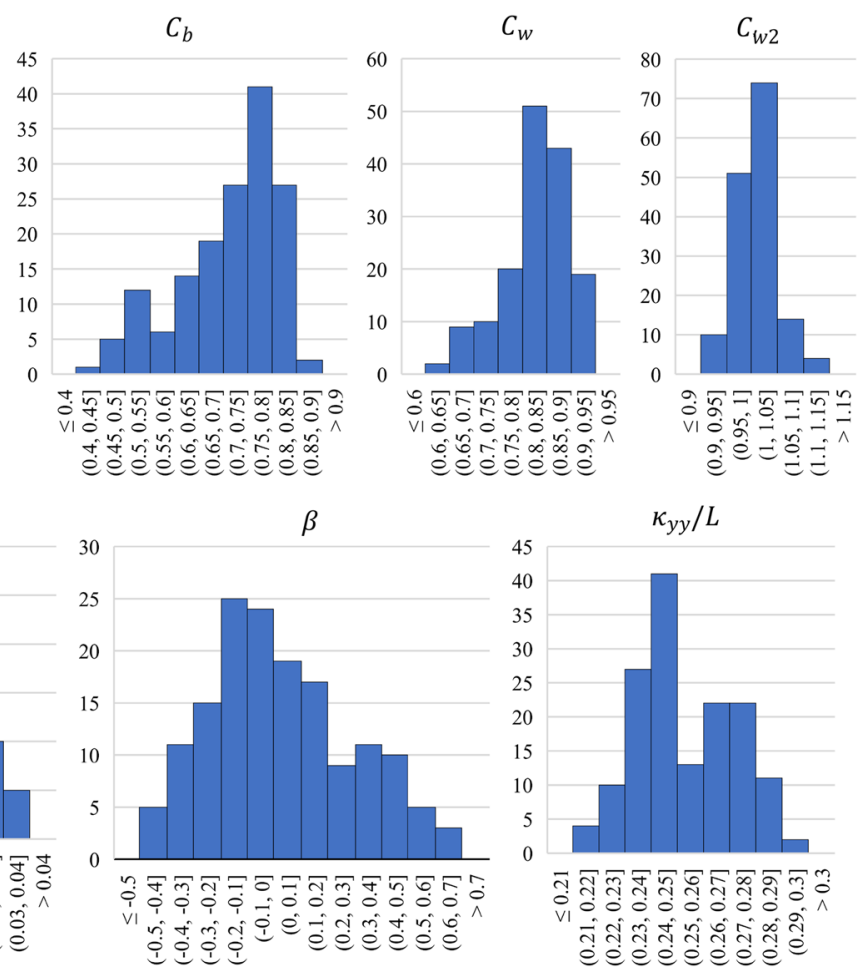

Fig. 11 Histogram of the non-dimensional hull-form parameters for the 154 actual merchant ships whose length is in the range of 50-400 $\mathrm{m}$ 
Table 2 Standard deviations of the principal parameters $\sigma_{p_{i}}$ calculated for 154 real ships

\begin{tabular}{llll}
\hline$B / L$ & 0.0135 & $C_{\mathrm{w} 2}^{\prime}$ & 0.0399 \\
$d / B$ & 0.0787 & $\mathrm{LCG} / L$ & 0.0239 \\
$C_{\mathrm{m}}$ & 0.0385 & $\mathrm{LCF} / L$ & 0.0294 \\
$C_{\mathrm{b}}$ & 0.101 & $\beta$ & 0.268 \\
$C_{\mathrm{w}}$ & 0.0676 & $k_{\mathrm{yy}} / L$ & 0.0192 \\
\hline
\end{tabular}

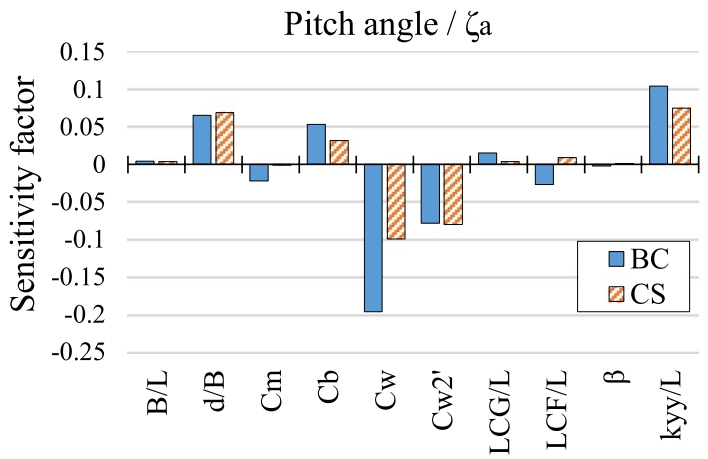

Fig. 12 Comparison of the sensitivity factor for the non-dimensional parameters for the maximum pitch angle in the head sea

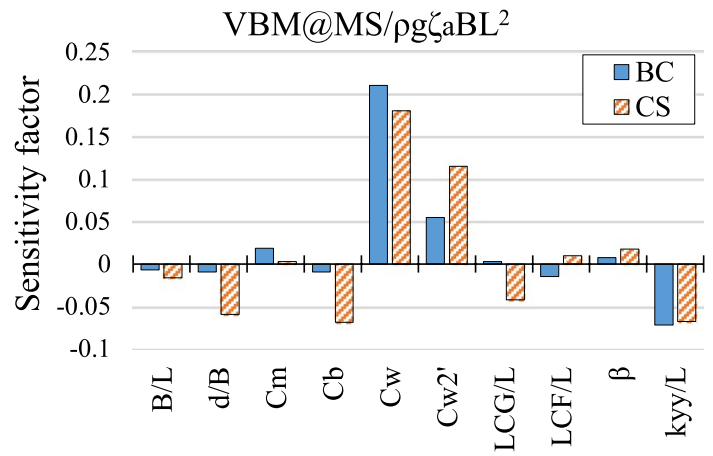

Fig. 13 Comparison of the sensitivity factor for the non-dimensional parameters for the maximum vertical bending moment amidship in the head sea

normalized by $\sigma_{p_{i}}$, the importance of the parameters cannot be compared because their fluctuation ranges are quite different. The values of $\sigma_{p_{i}}$ are listed in Table 2 .

Figures 12, 13, 14 show the sensitivity factors for the maximum values of the pitch motion, VBM, and HBM, respectively. The partial differential coefficient $\partial q_{j} / \partial p_{i}$ was calculated by the central difference method. This was achieved by varying the parameters within a micro range that can be considered as linear. Considering the results in Sect. 4 , for the HBM, $C_{\mathrm{w} 2}^{\prime}$ and $\beta$ were excluded from the parameters and they were calculated using the hull-form without longitudinal stretching, that is, $\alpha=1$.

We can observe the following from Figs. 12, 13, 14.

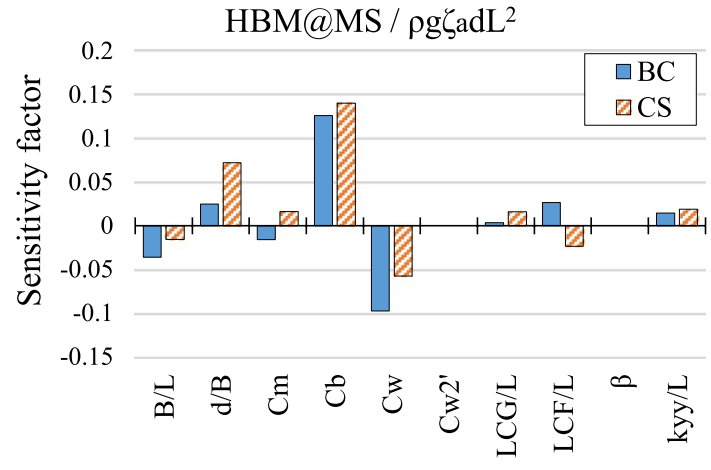

Fig. 14 Comparison of the sensitivity factor for the non-dimensional parameters except for $C_{\mathrm{w} 2}^{\prime}$ and $\beta$ for the maximum horizontal bending moment amidship in the quartering sea

a. For the pitch and VBM, the influence of $C_{\mathrm{w}}$ is the largest, followed by $C_{\mathrm{w} 2}^{\prime}, \kappa_{\mathrm{yy}} / L$. The effect of $C_{\mathrm{w} 2}^{\prime}$ is relatively strong for CS, that is, the slender ship. It is known that the VBM calculated based on linear theory is significantly affected by $C_{\mathrm{w}}$ [16], whereas $C_{\mathrm{w} 2}$ and $\kappa_{\mathrm{yy}}$ have not been considered in previous studies. $\kappa_{\mathrm{yy}}$ affects the rotational motion and the inertia force component of the hull-girder sectional forces due to the change in the weight distribution.

b. The sensitivity factor of $C_{\mathrm{w} 2}^{\prime}$ for the VBM of CS is approximately 0.12 . This implies that even if $C_{\mathrm{w}}$ is the same, the VBM changes due to the difference in the second moment of the waterplane area. The value of $C_{\mathrm{w} 2}^{\prime}$ is in the range $\pm 2.5 \sigma$ according to the histogram. Consequently, the VBM can change by approximately $\pm 30 \%(= \pm 2.5 \times 0.12)$. In contrast, the parameter $\beta$ that determines the rate of $C_{\mathrm{w} 2 \mathrm{a}}$ and $C_{\mathrm{w} 2 \mathrm{f}}$ does not significantly affect the ship response.

c. The tendency of the scale factors for the pitch and the VBM is almost inverse. This is because the inertia force due to the pitch motion and the fluid force cancel each other out and reduce the VBM, as we can understand from d'Alembert's principle. Therefore, there is a tradeoff between improving the seakeeping performance and reducing the wave-induced VBM.

d. For the HBM, the sensitivity factor of $C_{\mathrm{b}}$ is the largest, but it is not that large. In other words, the effect on the ship dimension against the HBM is relatively small. Note that this tendency is for the non-dimensional HBM that is divided by $d L^{2}$. That is, HBM is roughly proportional to $d L^{2}$, as shown in the classification society's formula [1].

e. Although the values of the sensitivity factors are different between $\mathrm{BC}$ and CS, the positive or negative trends are similar except for LCG and LCF. The reason why the tendencies of LCG and LCF are inverse is that the LCG of $\mathrm{BC}$ is located anterior to the $\mathrm{LCF}$, whereas it is the 
opposite for CS, as shown in Table 1. This indicates that the relative location of the LCF from LCG is an important parameter. In fact, such a relative location relates to the restoring coefficient of the heave-pitch interactive force.

\section{Conclusion}

This study developed a new mathematical hull-form that is called the Matsui hull-form. The Matsui hull-form is expressed as a explicit function of the half-breadth under waterline by 10 principal shape parameters: the length $L$, beam $B$, draft $d$, block coefficient $C_{\mathrm{b}}$, midship section area coefficient $C_{\mathrm{m}}$, waterplane area coefficient $C_{\mathrm{w}}$, second moment of the waterplane area coefficient $C_{\mathrm{w} 2}$, the longitudinal center of buoyancy LCB, the longitudinal center of floatation LCF, and a parameter $\beta$ related to the anterior-posterior asymmetry of the second moment of the waterplane area. The Matsui hull-form has the following features.

(i) A longitudinal stretching factor $\alpha$ was introduced so that the second moment of the waterplane area can be adjusted, which is dominant for the pitch motion and the VBM.

(ii) Instead of the fineness coefficients of the aft/fore parts, parameters LCB, LCF, and $\beta$ were introduced to express the anterior-posterior asymmetry of the ship, because these parameters are easy to handle and have greater physical significance.

(iii) The proposed hull-form can easily be generated from 10 principal shape parameters without offset data or any parent hull-form. Furthermore, the proposed hull-form which is generated from the same 10 parameters as the real ship has almost the same characteristics of the ship response in waves as the real ship. Therefore, the simple estimation of the seakeeping performance and the wave load can effectively be performed in the early stage of ship design.

(iv) It is also possible to systematically evaluate the variation in seakeeping performance and wave load of a ship with hull-form parameters.

(v) As the hull-form shape parameters can be varied widely, the hull-form can be extensively utilized for any type of mono-hull ship.

The ship responses in waves of the Matsui hullform were compared to those of the actual bulk carrier and container ship. In addition, a sensitivity analysis of the hull-form shape parameters was conducted. This investigation revealed the following findings. (vi) The ship responses in waves calculated using the Matsui hull-forms are equivalent to those of the actual bulk carrier and container ship with the same hull-form shape parameters.

(vii) Adjusting the second moment of the waterplane area is important for the vertical motions and the VBM.

(viii) In contrast, the non-stretched hull when $\alpha=1$ should be used for the ship responses that are related to the horizontal force, especially for the HBM, HSF, and TM.

(ix) The second moment of the waterplane area coefficient $C_{\mathrm{w} 2}$ is the second most important parameter after $\mathrm{C}_{\mathrm{w}}$ on pitch motion and the VBM. The waveinduced VBM might change by approximately $30 \%$ for slender ships in cases where $C_{\mathrm{w}}$ is the same but $C_{\text {w2 }}$ differs.

The proposed hull-form is defined under the waterline, because it is developed based on the Wigley hull-form. Although the hull-form under waterline is sufficient for the purpose of the simple estimation by linear calculation, the hull-form above waterline is important for evaluating the nonlinear effect of the wave loads by using a nonlinear solver. How to handle the hull-form above waterline needs to be examined in future studies.

\section{Appendix A: Development process of the proposed hull-form}

This appendix describes the development process of the proposed hull-form and derives Eq. $4-15$ based on the modified Wigley hull-form.

\section{Generalization of power indexes}

The power indexes of the modified Wigley hull-form (1) are generalized by introducing the non-negative real parameters $X_{1}, X_{2}, X_{3}, Z_{1}$, and $Z_{2}$ and a new anterior-posterior symmetric hull-form is expressed as follows.

$$
\begin{aligned}
\eta= & \left(1-\zeta^{Z_{1}}\right)\left(1-\xi^{X_{1}}\right)+\zeta^{Z_{1}}\left(1-\zeta^{Z_{2}}\right)\left(1-\xi^{X_{2}}\right)^{X_{3}} \\
& (0 \leq \xi \leq 1,0 \leq \zeta \leq 1),
\end{aligned}
$$

where $X_{1}, X_{2}$, and $X_{3}$ are the parameters related to the longitudinal shape, and $Z_{1}$ and $Z_{2}$ are related to the vertical shape. This equation does not have the term $c_{2}$ in Eq. 1 but the hull-form expression by the term is included in parameter $X_{1}$. The reason for using the same $Z_{1}$ in the first and second terms is to express the midship section as a simple power function: $\left.\eta\right|_{\xi=0}=1-\zeta^{Z_{1}+Z_{2}}$. The relationship between 
the power index parameters $Z_{1}, Z_{2}, X_{1}, X_{2}$, and $X_{3}$ and the fineness coefficients can be obtained by following equations.

$C_{\mathrm{w}}=\left.\int_{0}^{1} \eta\right|_{\zeta=0} \mathrm{~d} \xi=\frac{X_{1}}{1+X_{1}}$,

$C_{\mathrm{m}}=\left.\int_{0}^{1} \eta\right|_{\xi=0} \mathrm{~d} \zeta=\frac{Z_{1}+Z_{2}}{1+Z_{1}+Z_{2}}$,

$C_{\mathrm{b}}=\int_{0}^{1} \int_{0}^{1} \eta \mathrm{d} \zeta \mathrm{d} \xi=\frac{X_{1}}{1+X_{1}} \frac{Z_{1}}{1+Z_{1}}+S \frac{Z_{2}}{\left(1+Z_{1}\right)\left(1+Z_{1}+Z_{2}\right)}$,

where $S$ is the integral of the second term for Eq. 22 and defined as follows.

$S \equiv \int_{0}^{1}\left(1-\xi^{X_{2}}\right)^{X_{3}} \mathrm{~d} \xi=\frac{\Gamma\left(1+X_{3}\right) \Gamma\left(1+\frac{1}{X_{2}}\right)}{\Gamma\left(1+X_{3}+\frac{1}{X_{2}}\right)}$.

By solving Eqs. $23-25$ for $Z_{1}, Z_{2}$, and $X_{1}$, the following formulae can be obtained.

$X_{1}=\frac{C_{\mathrm{w}}}{1-C_{\mathrm{w}}}$.

$Z_{1}=\frac{C_{\mathrm{b}}-S C_{\mathrm{m}}}{C_{\mathrm{w}}-C_{\mathrm{b}}-S\left(1-C_{\mathrm{m}}\right)}$.

$Z_{2}=\frac{C_{\mathrm{m}}}{1-C_{\mathrm{m}}}-Z_{1}=\frac{\left(C_{\mathrm{w}} C_{\mathrm{m}}-C_{\mathrm{b}}\right) /\left(1-C_{\mathrm{m}}\right)}{C_{\mathrm{w}}-C_{\mathrm{b}}-S\left(1-C_{\mathrm{m}}\right)}$.

On the other hand, $X_{2}$ and $X_{3}$, which determine the longitudinal distribution of the cross-sectional area, are the internal DOFs and they cannot be determined by $C_{\mathrm{b}}, C_{\mathrm{w}}$, and $C_{\mathrm{m}}$. Hence, $X_{2}$ and $X_{3}$ can be chosen arbitrarily, such that $Z_{1}$ and $Z_{2}$ are not negative. The condition where $Z_{1}$ and $Z_{2}$ obtain a positive value can be replaced by the following condition.

$Z_{1} \geq 0$ when $Z_{2} \geq 0 \leftrightarrow S \frac{<}{>} C_{\mathrm{b}} / C_{\mathrm{m}}$ when $C_{\mathrm{b}} \leq C_{\mathrm{m}} C_{\mathrm{w}}$.

The sufficient conditions for $X_{2}$ and $X_{3}$ that satisfy condition (30) are given below.

$X_{2}=\frac{C_{\mathrm{b}}}{C_{\mathrm{m}}-C_{\mathrm{b}}}$ and $X_{3} \geq 1$.

This is because the following formula holds when $X_{3} \geq 1$.
$S=\frac{\Gamma\left(C_{\mathrm{m}} / C_{\mathrm{b}}\right) \Gamma\left(X_{3}+1\right)}{\Gamma\left(X_{3}+C_{\mathrm{m}} / C_{\mathrm{b}}\right)} \leq \frac{C_{\mathrm{b}}}{C_{\mathrm{m}}}$.

However, when $X_{2}$ is smaller than 1, the smoothness of the hull-form at the midship is lost. Therefore, in this study, the recommended values of $X_{2}$ and $X_{3}$ that satisfy condition (30) are proposed by using the following formulas.

$X_{2}=\max \left(N, \frac{C_{\mathrm{b}}}{C_{\mathrm{m}}-C_{\mathrm{b}}}\right)$ (recommended value).

$X_{3}=\left(C_{\mathrm{b}} / C_{\mathrm{m}}\right)^{N \bullet \operatorname{sgn}\left(C_{\mathrm{b}}-C_{\mathrm{m}} C_{\mathrm{w}}\right)}($ recommended value $)$.

By defining $X_{2}$ as in Eq. 33, $X_{2}$ does not get a value smaller than $N$, which is a real number greater than 1 . The larger $N$ is, the greater the longitudinal distribution of the cross-sectional area that is concentrated around the midship, and the longer the parallel part. The formula of $X_{3}$ was decided to satisfy the condition in (30) where $X_{2}=N$ and $X_{2}=\frac{C_{b}}{C_{\mathrm{m}}-C_{\mathrm{b}}}$.

Thus, the mathematical hull-form in which $C_{\mathrm{b}}, C_{\mathrm{m}}$, and $C_{\mathrm{w}}$ can be arbitrarily varied has been developed.

\section{Introduction of the parameter regarding the second moment of the waterplane area}

This section extends the hull-form (22) such that the second moment of the waterplane area can be adjusted independently from $C_{\mathrm{w}}$. The second moment of the waterplane area coefficient $C_{\mathrm{w} 2}$ is defined as Eq. 3. The value of $C_{\mathrm{w} 2}$ for the previous hull-form (22) is uniquely determined by $C_{\mathrm{w}}$ as follows.

$C_{\mathrm{w} 2}^{\alpha=1}=\left.12 \int_{0}^{1}\left(\frac{\xi}{2}\right)^{2} \eta\right|_{\xi=0} \mathrm{~d} \xi=\frac{C_{\mathrm{w}}}{3-2 C_{\mathrm{w}}}$.

Hence, it is necessary to make $C_{\mathrm{w} 2}$ independent of $C_{\mathrm{w}}$ by adding a DOF to the waterplane function in Eq. 22.

There are many ways to add the DOF to the function of the waterplane, but the simplicity of the function must not be lost in order to express the mathematical hull-form explicitly by the main hull-form shape parameters. Therefore, the $\xi$ -axis of Eq. 22 is stretched by the factor $\alpha$, and a new mathematical hull-form is defined as follows.

$$
\begin{aligned}
\eta= & \left(1-\zeta^{Z_{1}}\right)\left\{1-(\xi / \alpha)^{X_{1}}\right\}+\zeta^{Z_{1}}\left(1-\zeta^{Z_{2}}\right)\left\{1-(\xi / \alpha)^{X_{2}}\right\}^{X_{3}} \\
& (0 \leq \xi \leq \alpha, 0 \leq \zeta \leq 1)
\end{aligned}
$$

By defining this, it is possible to change $C_{\mathrm{w} 2}$ independently of $C_{\mathrm{w}}$ by stretching the hull-form, as shown in Fig. 3. 
The stretching factor $\alpha$ is determined by $C_{\mathrm{w}}$ and $C_{\mathrm{w} 2}$. Considering the definition of $C_{\mathrm{w}}$ and $C_{\mathrm{w} 2}$, the relational equation between $C_{\mathrm{w}}, C_{\mathrm{w} 2}$, and $\alpha$ can be derived as follows.

$$
\begin{aligned}
& \left\{\begin{array}{l}
C_{\mathrm{w}}=\int_{0}^{\alpha}\left\{1-(\xi / \alpha)^{X_{1}}\right\} d \xi=\frac{\alpha X_{1}}{X_{1}+1} \\
C_{\mathrm{w} 2}=12 \int_{0}^{\alpha}(\xi / 2)^{2}\left\{1-(\xi / \alpha)^{X_{1}}\right\} \mathrm{d} \xi=\frac{\alpha^{3} X_{1}}{X_{1}+3}
\end{array}\right. \\
& \leftrightarrow C_{\mathrm{w}} \alpha^{3}-3 C_{\mathrm{w} 2} \alpha+2 C_{\mathrm{w}} C_{\mathrm{w} 2}=0 .
\end{aligned}
$$

By solving this cubic equation using Vieta's formula [17], $\alpha$ can be expressed as follows.

$$
\alpha=2 \sqrt{C_{\mathrm{w} 2} / C_{\mathrm{w}}} \cos \left(\frac{\pi}{3}-\frac{1}{3} \tan ^{-1} \sqrt{\left(C_{\mathrm{w} 2} / C_{\mathrm{w}}^{3}\right)-1}\right) .
$$

From the square root of this formula, it is determined that $C_{\mathrm{w} 2}$ and $C_{\mathrm{w}}$ must satisfy the following inequality.

$C_{\mathrm{w} 2} \geq C_{\mathrm{w}}^{3}$

However, this limitation will not be a problem because tangle of $L C_{\mathrm{w}} \times B$, and the value of $C_{\mathrm{w} 2}$ increases as the waterplane shape becomes sharper.

For the power index parameters in Eq. 36, the following formulae are derived under the same considerations as in Section A.1.

$X_{1}=\frac{C_{\mathrm{w}}}{\alpha-C_{\mathrm{w}}}$.

$X_{2}=\max \left(N, \frac{C_{\mathrm{b}}}{\alpha C_{\mathrm{m}}-C_{\mathrm{b}}}\right)$ (recommended value).

$X_{3}=\left(C_{\mathrm{b}} / \alpha C_{\mathrm{m}}\right)^{N \cdot \operatorname{sgn}\left(C_{\mathrm{b}}-C_{\mathrm{m}} C_{\mathrm{w}}\right)}($ recommended value $)$.

$S=\alpha \frac{\Gamma\left(1+X_{3}\right) \Gamma\left(1+1 / X_{2}\right)}{\Gamma\left(1+X_{3}+1 / X_{2}\right)}$.

The formulae of $Z_{1}$ and $Z_{2}$ are the same as in Eqs. 28 and 29 because these parameters are not affected by longitudinal the equation $C_{\mathrm{w} 2}=C_{\mathrm{w}}^{3}$ holds when the waterplane is a rec-

Thus, the mathematical hull-form in which $C_{\mathrm{b}}, C_{\mathrm{m}}, C_{\mathrm{w}}$, and $C_{\mathrm{w} 2}$ can be arbitrarily varied has been developed.

\section{Introduction of the anterior-posterior asymmetric parameters}

The hull-form expressed by Eq. 36 is defined on either the aft side or the fore side of the midship. Accordingly, it is necessary to define $C_{\mathrm{b}}, C_{\mathrm{w}}$, and $C_{\mathrm{w} 2}$ to separately define the aft/fore part in order to generate an anterior-posterior asymmetric hull-form. Hereafter, all the variables with $\varepsilon a \varepsilon$ or $\varepsilon f \varepsilon$ in the subscript, such as $C_{\mathrm{ba}}$ and $C_{\mathrm{bf}}$, represent the values of the aft/fore part, and they are expressed together by using the symbol "**, such as $C_{\mathrm{b} * \text {. }}$

This section shows the expressions of the fineness coefficients $C_{\mathrm{b} *}, C_{\mathrm{w} *}$, and $C_{\mathrm{w} 2 *}$ defined for the aft/fore part by the anterior-posterior asymmetric parameters, $\mathrm{LCB}, \mathrm{LCF}$, and $\beta$, which is newly introduced.

The asymmetric mathematical hull-form based on Eq. 36 is defined as follows.

$\eta=\left\{\begin{array}{l}\left(1-\zeta^{Z_{1 \mathrm{a}}}\right)\left\{1-\left(|\xi| / \alpha_{\mathrm{a}}\right)^{X_{1 \mathrm{a}}}\right\} \\ +\zeta^{Z_{1 \mathrm{a}}}\left(1-\zeta^{Z_{2 \mathrm{a}}}\right)\left\{1-\left(|\xi| / \alpha_{\mathrm{a}}\right)^{X_{2 \mathrm{a}}}\right\}^{X_{3 \mathrm{a}}} \\ \text { for }-\alpha_{\mathrm{a}} \leq \xi \leq 0 \\ \left(1-\zeta^{Z_{1 \mathrm{f}}}\right)\left\{1-\left(|\xi| / \alpha_{\mathrm{f}}\right)^{X_{1 \mathrm{f}}}\right\} \\ +\zeta^{Z_{1 \mathrm{f}}}\left(1-\zeta^{Z_{2 \mathrm{f}}}\right)\left\{1-\left(|\xi| / \alpha_{\mathrm{f}}\right)^{X_{2 \mathrm{f}}}\right\}^{X_{3 \mathrm{f}}} \\ \text { for } 0 \leq \xi \leq \alpha_{f}\end{array}\right.$

This formula can be simplified by the symbol "*”, which is defined in Eq. 12, as in Eq. 4. The $\xi$-coordinates of the $\mathrm{LCF} \xi_{\mathrm{F}}(=\mathrm{LCF} /(L / 2))$ and $\mathrm{LCB} \xi_{\mathrm{B}}(=\mathrm{LCB} /(L / 2))$ of this hull-form can be obtained by the following formulae.

$$
\begin{aligned}
\xi_{\mathrm{F}} & =\left.\frac{1}{C_{\mathrm{w}}} \int_{-\alpha_{a}}^{\alpha_{f}} \frac{\xi}{2} \eta\right|_{\zeta=0} \mathrm{~d} \xi \\
& =\frac{1}{2 C_{\mathrm{w}}}\left\{-\frac{\alpha_{\mathrm{a}}^{2} C_{\mathrm{wa}}}{2\left(2 \alpha_{\mathrm{a}}-C_{\mathrm{wa}}\right)}+\frac{\alpha_{\mathrm{f}}^{2} C_{\mathrm{wf}}}{2\left(2 \alpha_{\mathrm{f}}-C_{\mathrm{wf}}\right)}\right\} .
\end{aligned}
$$

$\xi_{\mathrm{B}}=\frac{1}{C_{\mathrm{b}}} \int_{-\alpha_{\mathrm{a}}}^{\alpha_{\mathrm{f}}} \frac{\xi}{2} \int_{0}^{1} \eta \mathrm{d} \zeta \mathrm{d} \xi=\frac{1}{2 C_{\mathrm{b}}}\left[-\alpha_{a}^{2}\left\{C_{\mathrm{m} 1 \mathrm{a}} \frac{C_{\mathrm{wa}}}{2\left(2 \alpha_{\mathrm{a}}-C_{\mathrm{wa}}\right)}+C_{\mathrm{m} 2 a} S_{1 a}\right\}+\alpha_{\mathrm{f}}^{2}\left\{C_{\mathrm{m} 1 \mathrm{f}} \frac{C_{\mathrm{wf}}}{2\left(2 \alpha_{\mathrm{f}}-C_{\mathrm{wf}}\right)}+C_{\mathrm{m} 2 \mathrm{f}} S_{1 \mathrm{f}}\right\}\right]$.

stretching. By substituting $\alpha=1$ into Eqs. 36, 40-43, these equations correspond to Eqs. 22, 26-29. Consequently, the proposed hull-form is a natural enhancement of the hullform developed in Section A.1. where

$C_{\mathrm{m} 1 *} \equiv \int_{0}^{\alpha_{*}}\left(1-\zeta^{Z_{1 *}}\right) \mathrm{d} \zeta=\frac{C_{\mathrm{b} *}-S_{*} C_{\mathrm{m}}}{C_{\mathrm{w} *}-S_{*}}$. 
$C_{\mathrm{m} 2 *} \equiv \int_{0}^{\alpha_{*}} \zeta^{Z_{1 *}}\left(1-\zeta^{Z_{2 *}}\right) \mathrm{d} \zeta=\frac{C_{\mathrm{w} *} C_{\mathrm{m}}-C_{\mathrm{b} *}}{C_{\mathrm{w} *}-S_{*}}$.

$S_{1 *} \equiv \frac{1}{\alpha_{*}^{2}} \int_{0}^{\alpha_{*}} \xi\left\{1-\left(\frac{|\xi|}{\alpha_{*}}\right)^{X_{2 *}}\right\}^{X_{3 *}} \mathrm{~d} \xi=\frac{\Gamma\left(1+\frac{2}{X_{2 *}}\right) \Gamma\left(1+X_{3 *}\right)}{2 \Gamma\left(1+X_{3 *}+\frac{2}{X_{2 *}}\right)}$.

The relationship between $C_{\mathrm{w}}, C_{\mathrm{b}}$ for the entire ship and $C_{\mathrm{w} *}, C_{\mathrm{b} *}$ defined on the aft/fore part are expressed as follows, respectively.

$$
\begin{aligned}
& C_{\mathrm{w}}=\left.\frac{1}{2} \int_{-\alpha_{a}}^{\alpha_{\mathrm{f}}} \eta\right|_{\zeta=0} \mathrm{~d} \xi=\frac{C_{\mathrm{wa}}+C_{\mathrm{wf}}}{2} . \\
& C_{\mathrm{b}}=\frac{1}{2} \int_{-\alpha_{\mathrm{a}}}^{\alpha_{\mathrm{f}}} \int_{0}^{1} \eta \mathrm{d} \zeta \mathrm{d} \xi=\frac{C_{\mathrm{ba}}+C_{\mathrm{bf}}}{2} .
\end{aligned}
$$

From Eq. 44-51, $C_{\mathrm{w} *}$ and $C_{\mathrm{b} *}$ can be determined by $C_{\mathrm{w}}, C_{\mathrm{b}}, \mathrm{LCF}$, and LCB in principle; however, it is difficult to rigidly derive the explicit formulae of $C_{\mathrm{w} *}$ and $C_{\mathrm{b} *}$. Accordingly, we attempt to derive an approximate expression. First, by simplifying Eq. 45 assuming $\alpha_{*} \cong 1$, and solving for $C_{\text {wa }}$ in consideration of Eq. 50, the following formula is obtained.

$$
\begin{aligned}
& C_{\mathrm{wa}}=C_{\mathrm{w}}+\left(2 \xi_{\mathrm{F}} C_{\mathrm{w}}\right)^{-1} \pm \sqrt{\left(2 \xi_{\mathrm{F}} C_{\mathrm{w}}\right)^{-2}+\left(C_{\mathrm{w}}-2\right)^{2}} \\
& =C_{\mathrm{w}}-\xi_{\mathrm{F}} C_{\mathrm{w}}\left(C_{\mathrm{w}}-2\right)^{2}+O\left(\xi_{\mathrm{F}}^{3}\right) .
\end{aligned}
$$

Here, the higher-order term of LCF $O\left(\xi_{\mathrm{F}}^{3}\right)$ can be neglected, and the following approximated formulas are obtained.

$$
\left\{\begin{array}{l}
C_{\mathrm{wa}} \cong C_{\mathrm{w}}\left\{\begin{array}{l}
1-\xi_{\mathrm{F}}\left(C_{\mathrm{w}}-2\right)^{2} \\
C_{\mathrm{wf}} \cong C_{\mathrm{w}}
\end{array}\right\} 1+\xi_{\mathrm{F}}\left(C_{\mathrm{w}}-2\right)^{2}
\end{array}\right\}
$$

On the other hand, there are many parameters that influence $C_{\mathrm{b} *}$ as demonstrated in Eq. 46 , and it is even more
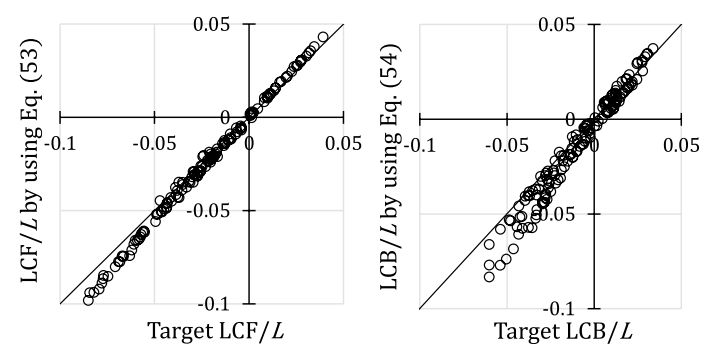

Fig. 15 Comparison of $\mathrm{LCF} / L$ and $\mathrm{LCB} / L$ between the target value and the value of the generated hull-form using the approximation formulae (53) and (54) for 154 ships. The hull-form parameters are set to the same values as those of 154 actual merchant ships difficult to solve for $C_{\mathrm{b} *}$. Therefore, for a simple approximation, the following formula is proposed in this study.

$\left\{\begin{array}{l}C_{\mathrm{ba}} \cong C_{\mathrm{b}}\left\{1-\xi_{\mathrm{B}}\left(C_{\mathrm{b}}-2\right)^{2}\right\} \\ C_{\mathrm{bf}} \cong C_{\mathrm{b}}\left\{1+\xi_{\mathrm{B}}\left(C_{\mathrm{b}}-2\right)^{2}\right\}\end{array}\right.$.

This formula is the same function as for $C_{\mathrm{w} *}$; hence, this assumes that the distribution function of the cross-sectional area under the waterline is a power function that is same as the waterline breadth distribution $\left(\left.\eta\right|_{\zeta=0}\right)$. Since Eq. 53 and 54 are approximated formulae, LCF and LCB of the generated hull-form by using Eq. 53 and 54 are slightly different from target value of them. The comparison of LCF and LCB between target value and the value of generated Matsui hull-form by using Eq. 53 and 54 for 154 ships, which are explained in Sect. 5.1, is shown in Fig. 15. It is confirmed that the error occurs up to about $0.025 \mathrm{~L}$, especially in LCB.

In order to make the LCF and LCB of the generated hull-form completely coincide with the target LCF and LCB, iterative calculations are required. Even in this case, the approximated formula 53 and 54 can be effectively used. In particular, in the case of LCF, the initial value of $C_{w a}$ is set to (53), and the incremental value of $C_{\text {wa }}$ is determined by the differential coefficient $\mathrm{d} C_{\mathrm{wa}} / \mathrm{d} \xi_{\mathrm{F}} \cong-C_{\mathrm{w}}\left(C_{\mathrm{w}}-2\right)^{2}$. Consequently, the $n+1$-th value $C_{\mathrm{wa}}^{(\mathrm{n}+1)}$ can be determined by the $n$-th value $C_{\mathrm{wa}}^{(\mathrm{n})}$ in the following formula.

$C_{\mathrm{wa}}^{(n+1)}=\left(\xi_{\mathrm{F}}^{\mathrm{target}}-\xi_{\mathrm{F}}^{(n)}\right)\left\{-C_{\mathrm{w}}\left(C_{\mathrm{w}}-2\right)^{2}\right\}+C_{\mathrm{wa}}^{(n)}$.

where $\xi_{\mathrm{F}}^{\text {target }}$ is the target value of LCF, and $\xi_{\mathrm{F}}^{(n)}$ is the $n$ -th value of LCF calculated using Eq. 45. After obtaining the value of $C_{\mathrm{wa}}, C_{\mathrm{wf}}$ can be calculated using Eq. 50 . Regarding to LCB, it can be considered in the same way as LCF. The initial value of $C_{\mathrm{ba}}$ is set to (54), and the $n+1$-th value $C_{\mathrm{ba}}^{(n+1)}$ can be determined by the following formula.

$C_{\mathrm{ba}}^{(n+1)}=\left(\xi_{\mathrm{B}}^{\mathrm{target}}-\xi_{\mathrm{B}}^{(n)}\right)\left\{-C_{\mathrm{b}}\left(C_{\mathrm{b}}-2\right)^{2}\right\}+C_{\mathrm{ba}}^{(n)}$.

where $\xi_{\mathrm{B}}^{\text {target }}$ is the target value of LCB, and $\xi_{\mathrm{B}}^{(n)}$ is the $n$ -th value of LCB calculated using Eq. 46.

Next, consider the second moment of the waterplane area of the aft part $C_{\mathrm{w} 2 \mathrm{a}}$ and the fore part $C_{\mathrm{w} 2 \mathrm{f}}$. The relationship between $C_{\mathrm{w} 2}$ for the entire ship and $C_{\mathrm{w} 2 *}$ defined for the aft/fore part is expressed as follows.

$C_{\mathrm{w} 2}=\left.6 \int_{\alpha_{a}}^{\alpha_{f}}\left(\frac{\xi}{2}\right)^{2} \eta\right|_{\zeta=0} \mathrm{~d} \xi=\frac{C_{\mathrm{w} 2 \mathrm{a}}+C_{\mathrm{w} 2 \mathrm{f}}}{2}$.

From this equation and the inequality in Eq. 39, the upper and lower limits of $C_{\mathrm{w} 2 \mathrm{a}}$ and $C_{\mathrm{w} 2 \mathrm{f}}$ are defined by $C_{\text {wa }}, C_{\mathrm{wf}}$, and $C_{\mathrm{w} 2}$ as follows. 


$$
\left\{\begin{array}{l}
C_{\mathrm{wa}}^{3}<C_{\mathrm{w} 2 \mathrm{a}}<2 C_{\mathrm{w} 2}-C_{\mathrm{wf}}^{3} \\
C_{\mathrm{wf}}^{3}<C_{\mathrm{w} 2 \mathrm{f}}<2 C_{\mathrm{w} 2}-C_{\mathrm{wa}}^{3}
\end{array} .\right.
$$

Instead of $C_{\mathrm{w} 2 *}$, let us denote a new parameter $\beta$, which is limited to the region of $-1<\beta<1$, and it is defined in the following equation.

$\beta=\frac{\left(C_{\mathrm{w} 2 \mathrm{f}}-C_{\mathrm{wf}}^{3}\right)-\left(C_{\mathrm{w} 2 \mathrm{a}}-C_{\mathrm{wa}}^{3}\right)}{\left(C_{\mathrm{w} 2 \mathrm{f}}-C_{\mathrm{wf}}^{3}\right)+\left(C_{\mathrm{w} 2 \mathrm{a}}-C_{\mathrm{wa}}^{3}\right)}$.

By defining this parameter, $C_{\mathrm{w} 2 *}$ can be described as in Eq. 15.

Finally, the formulae of the proposed hull-form, in which $C_{\mathrm{b}}, C_{\mathrm{m}}, C_{\mathrm{w}}, C_{\mathrm{w} 2}, \mathrm{LCB}, \mathrm{LCF}$, and $\beta$ can be varied arbitrarily, are obtained in Eqs. 4-15.

Acknowledgements The author would like to thank Dr. Toichi Fukasawa and Dr. Chikahisa Murakami in National Maritime Research Institute for their advice and careful proofreading of this manuscript. The author also thanks Mr. Kyohei Shinomoto and Mr. Kei Sugimoto in ClassNK for providing the main hull-form parameters of the 154 actual ships.

Open Access This article is licensed under a Creative Commons Attribution 4.0 International License, which permits use, sharing, adaptation, distribution and reproduction in any medium or format, as long as you give appropriate credit to the original author(s) and the source, provide a link to the Creative Commons licence, and indicate if changes were made. The images or other third party material in this article are included in the article's Creative Commons licence, unless indicated otherwise in a credit line to the material. If material is not included in the article's Creative Commons licence and your intended use is not permitted by statutory regulation or exceeds the permitted use, you will need to obtain permission directly from the copyright holder. To view a copy of this licence, visit http://creativecommons.org/licenses/by/4.0/.

\section{References}

1. IACS (2019) Common structural rules for bulk carriers and oil tankers

2. Bales NK (1980) Optimizing the seakeeping performance of destroyer-type hull. 13th Symposium on Naval Hydrodynamics, Tokyo

3. Sayli A, Alkan AD, Uysal AO (2014) Automatic elimination of ship design parameters based on data analysis for seakeeping performance. Brodogradnja 65:15-33
4. Cakici F, Aydin M (2014) Effects of hull form parameters on seakeeping for YTU gulet series with cruiser stern. Int J Nav Archit Ocean Eng 6:700-714

5. Jensen JJ, Mansour A (2002) Estimation of ship long-term waveinduced bending moment using closed-form expressions. Int $\mathbf{J}$ Marit Eng 2002:41-55

6. Jensen JJ, Mansour AE, Olsen AS (2004) Estimation of ship motions using closed-form expressions. Ocean Eng 31:61-85

7. Lackenby H (1950) On the systematic geometrical variation of ship forms. Trans INA 92:289-316

8. 17th ITTC Resistance Committee report (1983) Cooperative experiment on Wigley parabolic model in Japan. ITTC

9. Ciortan C, Wanderley J, Guedes Soares C (2007) Turbulent freesurface flow around a Wigley hull using the slightly compressible flow formulation. Ocean Eng 34:1383-1392

10. Journée JMJ (1992) Experiments and calculations on four Wigley Hullforms. Faculty of Mechanical Engineering and Marine Technology, Ship Hydrodynamic Lab, Delft University of Technology, Delft

11. Kashiwagi M, Endo K, Yamaguchi H (2005) Wave drift forces and moments on two ships arranged side by side in waves. Ocean Eng 32:529-555

12. Guo H, Wang J, Wan D, Hu C (2019) Benchmark computations on motion responses and bow waves of the ship in regular waves Proceedings of the 2019 International Ocean and Polar Engineering Conference, pp. 2871-2878

13. Kapsenberg GK (2005) Finding the hull form for given seakeeping characteristics. 26-30, Lisbon, pp. 867-874

14. Matui S, Shinomoto K, Sugimoto K, Ashida S (2020) Development of simplified formula of Froude-Krylov force of 6-DOFs acting on Monohull Ship. J Jpn Soc Nav Archit Ocean Eng 32:9-20 (in Japanese)

15. Matsui S, Murakami C, Hayashibara H, Fueki R (2019) Development of direct load and structure analysis and evaluation system on whole ship DLSA-basic for ship structural design. Papers of National Maritime Research Institute, pp. 19-3 (in Japanese)

16. IACS (2015) Longitudinal strength standard for container ships. Unified Requirement S, 11A

17. Shelbey S (ed) (1975) CRC standard mathematical tables. CRC Press, Boca Raton

Publisher's Note Springer Nature remains neutral with regard to jurisdictional claims in published maps and institutional affiliations. 